\title{
RESULTS OF ACUTE PURULENT CHOLANGITIS TREATMENT WITH GENETIC ENGINEERING ANALOGUE OF DORNAZE-ALPHA NATURAL ENZYME
}

DOI: 10.36740/WLek202009214

\author{
Mariya I. Pokidko, Igor M. Vovchuk, Oleh A. Yarmak \\ NATIONAL PIROGOV MEMORIAL MEDICAL UNIVERSITY, VINNYTSIA, UKRAINE
}

\begin{abstract}
The aim: To evaluate the effectiveness of the proposed method of surgical treatment of patients with acute purulent cholangitis.

Materials and methods: The research is based on the analysis of the treatment results in 104 patients with acute purulent cholangitis. The volume of surgical interventions on the biliary tract in patients was as follows: endoscopic papillosphincterotomy (EPST) + naso-biliary drainage; EPST + laparoscopic cholecystectomy; cholecystectomy + choledocholithotomy + drainage of the common bile duct.

Results: The APACHE- 2 scale assessment for patients in the control group was $12,80 \pm 1,73$, with the SOFA scale $-4,32 \pm 0,31$ points. Accordingly, the assessment for patients in the main group with the APACHE- 2 scale is $11.76 \pm 0.81$, with the SOFA scale $-4.33 \pm 0.79$ points. The results obtained in both the control and the main group indicate that the physiological reactions of the organism to the disease, treatment, development of organ dysfunction are reflected in the integrated severity assessment scales.

Conclusion: The performed analysis of clinical and laboratory results of treatment in both groups established the high efficiency of the proposed treatment method in patients with acute purulent cholangitis, which promotes the more rapid medical and social rehabilitation in this category of patients.
\end{abstract}

KEY WORDS: cholangitis, biliary tract surgical procedures, endoscopic papillotomy

Wiad Lek. 2020;73(9 p. II):1973-1976

\section{INTRODUCTION}

According to $\mathrm{WHO}$, acute purulent cholangitis (APC) without surgical intervention leads to lethal consequences in $98.7 \%$ of patients. Purulent inflammation of the intrahepatic bile ducts is accompanied by pronounced dystrophic changes in the liver parenchyma. Microscopically, the walls of the duct are infiltrated with leukocytes, the spread of the purulent process to the surrounding tissue (pericholangitis) and formation of the so-called cholangitic abscesses are possible. In case of purulent cholangitis the suppuration and necrosis with perforation leads to the development of biliary or biliary-purulent peritonitis. Healing of purulent ulcerative cholangitis is followed by granulation and epithelization of ulcers with subsequent sclerosis and deformation of the duct $[1,2,3,4]$.

The penetration of microbial bodies from bile into the systemic circulation accompanied by hemodynamic disorders, which in clinical practice manifests itself in the form of acute biliary septic shock. According to the research, biliary sepsis develops in $39.1 \%$ of patients with acute cholangitis, moreover, a fulminant course of the disease developement is observed more often $[5,6]$.

Over the past three decades, optimization of the traditional ways of APC treatment has taken place, namely, new surgical techniques have been introduced: laparoscopic cholecystectomy, EPST, transcutaneous transhepatic cholangiostomy. Analyzing data from various sources, surgical manipulations on the biliary tract in patients are accompanied by complica- tions in $8.3-43 \%$ of cases and the mortality rate of 6.2 to $28.6 \%$ of cases. EPST with nasobiliary drainage is one of the most effective methods of cholangitis treatment, and the percentage of recovery without complications is $83.5 \%$. This method proved to be safe in the category of operated patients over the age of 60 years. The incidence of fatalities is $1.5 \%$. Taking into account the disadvantages of previous treatment methods, we have proposed a new way of optimizing surgical intervention and postoperative correction $[7,8,9,10]$.

Recombinant human DNA-ase (Dornase-alpha) is a genetic engineering analogue of a natural human enzyme that cleaves the extracellular DNA, so the targeted effect of Dornase- $\alpha$ is to effectively degrade the extracellular DNA by hydrolysis, which causes the degradation of the pathological secretion, exhibits anti-inflammatory properties in the form of reduction of edema and hyperemic reactions.

In order to confirm the effectiveness of the gene-engineering variant of the natural enzyme Dornase-alpha in the treatment complex of acute purulent cholangitis, a number of studies were carried out at the Department of Surgery No. 2 clinic, Vinnitsa National Pirogov Memorial Medical University.

\section{THE AIM}

The aim is to evaluate the effectiveness of the proposed method of treatment in patients with acute purulent cholangitis. 
Table I. Methods of surgical intervention in patients with $\mathrm{APC}(\mathrm{n}=50)$

\begin{tabular}{ccc} 
Type of surgery & Control group (n=50) & Percents \\
\hline EPST & 28 & $56 \%$ \\
\hline EPST + laparoscopic cholecystectomy & 8 & $16 \%$ \\
\hline cholecystectomy + choledocholithotomy + drainage of the common bile duct & 14 & $28 \%$ \\
\hline
\end{tabular}

Table II. Comparative characteristics of cytolysis and cholestasis syndrome indicators in the control and the main groups of patients $(n=104)(M \pm m)$

\begin{tabular}{|c|c|c|c|c|c|c|}
\hline Indicator & Group & 1 day & 5 day & 9 day & 12 day & Discharge \\
\hline \multirow{2}{*}{$\begin{array}{l}\text { Total bilirubin, } \\
\text { mkmoll/l }\end{array}$} & Control group & $308,5 \pm 18,46^{*}$ & $188,42 \pm 13,48^{*}$ & $107,96 \pm 6,28$ & $68,8 \pm 3,23^{*}$ & $26,18 \pm 1,18^{*}$ \\
\hline & Main group & $289,29 \pm 11,01^{*}$ & $191,04 \pm 10,07^{*}$ & $90,20 \pm 4,23^{*}$ & $53,90 \pm 1,94^{*}$ & $18,61 \pm 0,58^{*}$ \\
\hline \multirow{2}{*}{$\begin{array}{l}\text { Direct bilirubin, } \\
\mathrm{mcmol} / \mathrm{l}\end{array}$} & Control group & $228,53 \pm 14,62^{*}$ & $122,53 \pm 10,22^{*}$ & $57,19 \pm 3,79^{*}$ & $33,49 \pm 2,56^{*}$ & $10,32 \pm 0,69^{*}$ \\
\hline & Main group & $209,54 \pm 10,56^{*}$ & $112,62 \pm 9,13^{*}$ & $49,03 \pm 4,34^{*}$ & $23,06 \pm 1,26^{*}$ & $6,52 \pm 0,44^{*}$ \\
\hline \multirow{2}{*}{$\begin{array}{l}\text { Indirect bilirubin, } \\
\mathrm{mcmol} / \mathrm{l}\end{array}$} & Control group & $80,01 \pm 5,08^{*}$ & $64,8 \pm 4,6^{*}$ & $48,45 \pm 3,57^{*}$ & $34,0 \pm 2,6^{*}$ & $16,26 \pm 1,21^{*}$ \\
\hline & Main group & $80,87 \pm 1,58^{*}$ & $74,7 \pm 3,09 *$ & $53,49 \pm 2,14^{*}$ & $30,84 \pm 1,94^{*}$ & $12,18 \pm 0,61^{*}$ \\
\hline \multirow{2}{*}{ ALT, mmol/l } & Control group & $7,14 \pm 0,067^{*}$ & $4,45 \pm 0,06^{*}$ & $2,56 \pm 0,037^{*}$ & $1,56 \pm 0,4^{*}$ & $1,03 \pm 0,013^{*}$ \\
\hline & Main group & $5,06 \pm 0,04^{*}$ & $3,68 \pm 0,05^{*}$ & $2,31 \pm 0,03^{*}$ & $1,38 \pm 0,03^{*}$ & $0,63 \pm 0,02^{*}$ \\
\hline \multirow{2}{*}{$\begin{array}{c}\text { AST, } \\
\mathrm{mmol} / \mathrm{l}\end{array}$} & Control group & $5,3 \pm 0,027^{*}$ & $2,99 \pm 0,014^{*}$ & $1,63 \pm 0,011^{*}$ & $1,107 \pm 0,024^{*}$ & $0,79 \pm 0,014^{*}$ \\
\hline & Main group & $4,89 \pm 0,03^{*}$ & $2,07 \pm 0,01^{*}$ & $1,28 \pm 0,02^{*}$ & $0,99 \pm 0,02^{*}$ & $0,51 \pm 0,02^{*}$ \\
\hline
\end{tabular}

Note. * - for the average parameter value compared with the norm $p<0,05$

\section{MATERIALS AND METHODS}

The research is based on the analysis of the treatment results in 104 patients with acute purulent cholangitis (APC) who were managed in the period from 2010 to 2017 in the surgical clinic of the Department of Surgery №2 of Vinnitsa National Pirogov Memorial Medical University and Vinnytsa center of liver, extrahepatic bile ducts and pancreatic surgery. Clinical studies were carried out in compliance with the basic provisions of the Council of Europe Convention on Human Rights and Biomedicine (04.04.1997), the Helsinki Declaration of the World Medical Association on the Ethical Principles of Scientific Medical Research with Human Participation (1964-2000) and the Order of the Ministry of Health of Ukraine No. 281 of November 1, 2000.

The volume of surgical interventions on the biliary tract in patients was as follows: endoscopic papillosphincterotomy (EPST) + naso-biliary drainage; EPST + laparoscopic cholecystectomy; cholecystectomy + choledocholithotomy + drainage of the common bile duct.

The control group consisted of 50 patients with APC. The obtained data were compared with the main group of 54 patients. In the main group of patients, we proposed a new method of treating APC, which comprises the use of Pulmozim (active ingredient - Dornase-alpha) for lavage of the comon bile duct drainage in APC, given that purulent exudate contains a high concentration of extracellular DNA - a viscous polyanion, which accumulates as a result of leukocytes destruction within the inflammatory process. Taking into account the disadvantages of previous treatment methods, we proposed the way to optimize surgical intervention and postoperative correction. The patent of Ukraine No. 8773/ZU/18 for the utility model "A method of treatment of acute purulent cholangitis" was obtained. The method is carried out in the following manner: EPST + nasobiliary drainage is performed. Corrective treatment, carried out by introducing of the Dornase-alpha solution in $0.9 \% \mathrm{NaCl}$ into the nasobiliary drainage for 5 days (1 time per day) of the postoperative period, together with complex multicomponent intensive care according to the Order of the Ukraine Ministry of Health No. 297 dated 02.04.10. "Standards of medical care for patients with urgent surgical diseases of the abdominal cavity".

An assessment of systemic inflammation was performed according to the recommended criteria of the Chicago Coordinatory Conference on Intensive Care (USA, 1992), according to which the systemic inflammatory response syndrome (SIRS) was determined in the presence of two or more symptoms.

Determination of the severity of the diagnosed APC was based on assessing the patient's condition according to the APACHE 2 and SOFA scales.

\section{RESULTS AND DISCUSSION}

Indications for emergency and urgent surgical intervention were: destructive forms of calculous cholecystitis; cholangitis, resistant to conservative therapy; mechanical jaundice; combined destructive inflammatory pathology of extrahepatic bile ducts (destructive cholecystitis, cholangitis and mechanical jaundice); acute blockade of the common bile duct terminal part (Table I). The volume of surgical interventions on the biliary tract in patients was as follows:

- EPST + nasobiliary drainage;

- EPST + laparoscopic cholecystectomy;

- cholecystectomy + choledocholithotomy + drainage of the common bile duct. 
Table III. Duration of the hospital stay of patients with acute purulent cholangitis, depending on the treatment metod $(\mathrm{n}=104)$

\begin{tabular}{ccc} 
Criteria & Control group $(\mathbf{n}=\mathbf{3 3})$ & Main group $(\mathbf{n}=\mathbf{3 1})$ \\
\hline Duration of the hospital stay & $16,87 \pm 3,08^{*}$ & $10,0 \pm 1,85$ \\
\hline Duration of the ICU treatment & $3,1 \pm 0,42^{*}$ & $1,7 \pm 0,32$ \\
\hline
\end{tabular}

Note. ${ }^{*}-p<0,05$, the reliability of differences compared to the main group.

The assessment of patients in the control group according to APACHE-2 - 12,80 $\pm 1,73$, with the SOFA scale - 5,32 $\pm 0,31$ points. Accordingly, the assessment for patients in the main group with the APACHE-2 scale showed 11.76 \pm 0.81 , with the SOFA scale $-4.33 \pm 0.79$ points $(\mathrm{p}<0,01)$.

The dynamics of changes in the indicators of the cytolysis and cholestasis syndrome in patients of the control and the main groups during the application of traditional and optimized complex therapy methods was analyzed (Table II).

The analysis of the dynamic changes of the total bilirubin showed that before the first day of treatment the difference between the control $(308.5 \pm 18.46 ; 188.42 \pm 13.48)$ and the main $(289.29 \pm 11.01,191.04 \pm 10.07)$ group was not determined ( $p>0.05)$. However, since the ninth day of treatment and at the time of its completion, the difference was reliable $(\mathrm{p}<0.05)$ between the next indices: $(107.96 \pm 6,28 ; 68.8 \pm$ $3.23 ; 26.18 \pm 1.18)(90.20 \pm 4.23 ; 53.90 \pm 1.94 ; 18.61 \pm 0.58)$.

The study of the dynamics of changes in direct bilirubin in patients from control and main groups showed that the reliable difference in values was not determined. During the first day of treatment $(228.53 \pm 14.62,209.54 \pm 10.56$ ( $p>0.05$ ) and during the entire subsequent term until the end of treatment the difference was reliable $(122.53 \pm 10.22$; $57.19 \pm 3.79 ; 33.49 \pm 2.56 ; 10.32 \pm 0.69),(112.62 \pm 9.13$, $49.03 \pm 4.34,23.06 \pm 1.26,6.52 \pm 0.44)(\mathrm{p}<0.05)$.

The analysis of the dynamic changes of ALT in patients within control and main groups found that by the ninth day of treatment the reliable difference between the groups was not observed $(\mathrm{p}>0.05)(7.14 \pm 0.067,4.45 \pm 0.06,2.56$ $\pm 0,037)(5,06 \pm 0,04 ; 3,68 \pm 0,05 ; 2,31 \pm 0,03)(8,15 \pm 0,36$; $7,18 \pm 0,39)$, but from the twelfth day of treatment and till its completion, the difference was reliable $(1.56 \pm 0.4 ; 1.03$ $\pm 0.013)(1.38 \pm 0.03 ; 0.63 \pm 0.02)(\mathrm{p}<0.05)$.

When comparing the duration of the hospital stay as well as the duration of ICU treatment in the main and control group the significantly better results were observed in the group with the proposed treatment method (Table III).

The results obtained in both the control and the main groups indicate that the physiological reactions of the organism to the disease, treatment, development of organ dysfunction are reflected in the integrated severity assessment scales. Along with the other indicators, a significant decrease in AST was determined. During the first day, this indicator was stably high $(5.3 \pm 0.027)(4.89 \pm 0.03)$. On the fifth day after surgery, AST decreased significantly (1.99 $\pm 0.014)(1.97 \pm 0.01)$. Subsequently, in the main group, the AST level was lower throughout the follow-up period $(\mathrm{p}<0.05)$, before discharge it was $0.51 \pm 0.02$, compared to the rate, observed in the studied patients $(0.79 \pm 0.014)$ who were treated using traditional methods.

On the basis of the cytolysis and cholestasis syndromes analysis in patients within control and main groups, the high effectiveness of the proposed treatment method for patients in the experimental group was established in comparison to the traditional methods used in patients of the control group.

\section{CONCLUSIONS}

1. The use of low-traumatic miniinvasive technologies for the prevention of postoperative and purulent-necrotic complications in patients of the main group led to a significant improvement in the results of treatment compared to the control group. The comparative estimation of treatment in patients with acute purulent cholangitis showed that the use of the developed method and its inclusion in the program of integrated optimized treatment allowed to reduce the period of inpatient treatment of patients with acute purulent cholangitis by 6.8 days (from 16.87 to 10 ).

2. The conducted analysis of clinical and laboratory results of treatment of patients in the control and the main groups has established the high efficiency of the proposed treatment method for patients with acute purulent cholangitis, which forms the conditions for more rapid medical and social rehabilitation of this category of patients.

\section{REFERENCES}

1. Seo N., Kim S.Y., Lee S.S., Byun J.H. et al. Sclerosing cholangitis: clinicopathologic features, imaging spectrum, and systemic approach to differential diagnosis. Korean J Radiol. 2016;17:25-38. 10.3348/ kj.2016.17.1.25

2. Tanaka A., Tazuma S., Okazaki K., Tsubouchi H. et al. Nationwide survey for primary sclerosing cholangitis and lgG4-related sclerosing cholangitis in Japan. J Hepatobiliary Pancreat Sci. 2014;21:43-50. 10.1002/jhbp.50.

3. Walter D., Hartmann S., Herrmann E., Peveling-Oberhag J. et al. Eosinophilic cholangitis is a potentially underdiagnosed etiology in indeterminate biliary stricture. World J Gastroenterol. 2017;23:10441050. 10.3748/wjg.v23.i6.1044.

4. Nishino T., Hamano T., Mitsunaga Y., Shirato I. et al. Clinical evaluation of the Tokyo Guidelines 2013 for severity assessment of acute cholangitis.J Hepatobiliary Pancreat Sci. 2014;21:841-849. 10.1002/jhbp. 189.

5. Patel H., Gaduputi V., Chelimilla H., Makker J. et al. Acute cholangitis: does the timing of ERCP alter outcomes? J Pancreas. 2016;17:504-509.

6. Kwan K.E.L., Shelat V.G., Tan C.H. Recurrent pyogenic cholangitis: a review of imaging findings and clinical management. Abdom Radiol (NY). 2017;42:46-56. 10.1007/s00261-016-0953-y.

7. Lunder A.K., Hov J.R., Borthne A., Gleditsch J. et al. Prevalence of sclerosing cholangitis detected by magnetic resonance cholangiography in patients with long-term inflammatory bowel disease. Gastroenterology. 2016;151:660669.e4. 10.1053/j. gastro.2016.06.02. 
8. Gornals J.B., Consiglieri C.F., Bergamino M.A. Double pigtail for preventing ascending cholangitis after endoscopic ultrasonographyguided choledochoduodenostomy with lumen-apposing metal stent. Dig Endosc. 2016;28:100. 10.1111/den.12548.

9. Shenoy S.M., Shenoy S., Gopal S., Tantry B.V. et al. Clinicomicrobiological analysis of patients with cholangitis. Indian JMed Microbiol.2014;32:157160. 10.4103/0255-0857.129802.

10. Ray S., Sanyal S., Das K., Ghosh R. et al. Outcome of surgery for recurrent pyogenic cholangitis: a single center experience. HPB (0xford) 2016;18:821-826.10.1016/j.hpb.2016.06.001.

\section{ORCID and contributionship:}

Mariya I. Pokidko: 0000-0002-1640-7230 A,E,F

Igor M. Vovchuk: 0000-0002-0613-9383 B,C

Oleh A. Yarmak: 0000-0002-4103-7614 ${ }^{D}$

\section{Conflict of interest:}

The Authors declare no conflict of interest.

\section{CORRESPONDING AUTHOR}

\section{Oleh A. Yarmak}

National Pirogov Memorial Medical University

56 Pirogova Vulytsia, 21000 Vinnytsia, Ukraine

tel:+380634604538; +4915257506075

e-mail:yarmakoleg@gmail.com

Received: 27.10 .2019

Accepted: 09.07.2020

A - Work concept and design, B - Data collection and analysis, C - Responsibility for statistical analysis,

D-Writing the article, $\mathbf{E}$-Critical review, $\mathbf{F}$ - Final approval of the article 